\title{
Ironía y descentramiento en los Artefactos de Nicanor Parra y Guillermo Tejeda*
}

\author{
Gabriel Villaroel ${ }^{* *}$
}

\begin{abstract}
Recibido: 3 de septiembre de 2013
Evaluado: 20 de septiembre de 2013

Aceptado: 7 de octubre de 2013
\end{abstract}

\section{RESUMEN}

En este artículo se desarrollará la heterogénea pluralidad de pensamiento que reina en las frases de los Artefactos en relación con las imágenes de Guillermo Tejera y la necesidad de estudiarlas como parte de un mismo proyecto. Nicanor Parra utiliza una distancia irónica de su "yo" para esgrimir en su obra una amplia y contradictoria gama de ideas que encuentran un nuevo desarrollo en el diseño visual que las enmarca. Las imágenes permiten abrir nuevos significantes dentro de la subversión del discurso poético operada por el chileno. Para desarrollar este tema, se utilizará como principal ejemplo la irreverencia del poeta frente a la política de izquierda y derecha durante los álgidos y comprometidos años setenta.

Palabras clave: Nicanor Parra, Guillermo Tejeda, artefactos, ironía, poesía visual.

* Artículo de reflexión. Investigación en el ámbito de la Literatura Latinoamericana, realizada en la Georgetown University.

** Magíster en Estudios Literarios por la Universidad de Colombia. Actualmente es candidato doctoral del programa Spanish Literature and Cultural Studies de la Georgetown University, Washington. Su campo de estudio es la literatura latinoamericana de los siglos xix y xx. Correo electrónico: igv3@georgetown.edu 


\title{
Irony and Eccentricity in the Artefactos by Nicanor Parra and Guillermo Tejeda
}

\begin{abstract}
This essay will develop the diverse plurality of the ideas behind the Artefactos in relation to in the images created by Guillermo Tejera. It will try to point out the necessity of studying them together as a whole. Nicanor Parra uses an ironic distance from his self to exhibit a wide and diverse range of ideas that find a field to develop within the images that go with them. The images allow new meanings to open and subvert the regular course of the poetic discourse. To exemplify this subject, this essay will use primarily the Chilean poet's irreverence towards left and right wing politics during the seventies.
\end{abstract} Received: September 3, 2013 Evaluated: September 20, 2013 Accepted: October 7, 2013

Keywords: Nicanor Parra, Guillermo Tejeda, Artefactos, Irony, Visual Poetry. 


\section{Ironia e descentramento nos Artefactos de Nicanor Parra y Guillermo Tejeda}

Recebido: 03 de setembro de 2013

Avaliado: 20 de setembro de 2013 Aceito: 7 de outubro de 2013

\section{RESUMO}

Nesse artigo desenvolve-se a heterogênea pluralidade do pensamento que predomina nas frases dos Artefactos com relação com as imagens de Guillermo Tejera e a necessidade de estudá-las como fazendo parte do mesmo projeto. Nicanor Parra usa uma distância irônica de seu "eu" esgrimir em sua obra uma ampla e contraditória gama de idéias que encontram um novo desenvolvimento no design visual que tem-las encaixado. As imagens permitem abrir novos significantes dentro da subversão do discurso poético operado pelo chileno. Para desenvolver este tema, utilizar-se-á como exemplo principal a irreverência do poeta frente à política de esquerda e direita durante o cruciais e comprometidos anos setenta.

Palabras-chave: Nicanor Parra, Guillermo Tejeda, artefatos, ironia, poesia visual. 


\section{INTRODUCCIÓN}

En el breve relato "Everything and nothing", Borges (1989) imaginó a un Shakespeare que, angustiado por su propia vacuidad, ingenia voces, personajes, sonetos y tragedias; se convierte en artífice de elaborados sueños de un soñador ausente que, no obstante, lo rodearon de admiración. Luego de muchos años, consciente del ardid e incapaz de continuarlo, abandona su oficio, y en el umbral de la muerte se lamenta ante el Creador: "Yo, que tantos hombres he sido en vano, quiero ser uno y yo" (132). La imagen borgeana de Shakespeare es la de un genial artífice de máscaras; la prodigiosa diversidad de sus obras y su capacidad para darle vida a voces contradictorias es un reflejo de la ausencia de una voz propia. Shakespeare, de acuerdo con esta representación, puede perfilar numerosas naturalezas humanas, pero permanece exiliado de la suya propia. Por eso, los estudiosos consideran que no hay un proyecto único en el pensamiento shakesperiano; es un hombre que coteja todas las ideas, las más ortodoxas y heterodoxas, sin apropiarse de ninguna.

Nicanor Parra es un confeso admirador del bardo (tradujo King Lear, y supuestamente prepara un poemario titulado El marica de Shakespeare), pero más allá de la devoción que le profese como escritor, ha jugado con la contradicción deliberada, al punto de llegar a cierta despersonalización que difumina al sujeto poético enunciador. Quizás el momento de su obra donde esta propuesta ha sido llevada más al extremo es en los Artefactos. Así lo observa Van Hooft (1974):

If poetry is to succeed, especially in the case of the Artefactos, then it must reflect the whole gamut of possible political statements that might be made by the multiple personae. In other words, it should be possible to find both revolutionary and reactionary statements in it. (p. 79)

La fragmentación no solo es verdadera en un nivel de ideología política; los artefactos lanzan sus esquirlas en las direcciones más diversas, atentan contra la revolución y la contrarrevolución, la poesía y la antipoesía, la virtud y la infamia. La colección representa no el postulado homogéneo de un pensamiento, sino una dispersa galería de esbozos que, en el fondo, niegan la posible unidad del sujeto tras las palabras.

Según opina Ibáñez-Langlois (1972), detrás de esta labor de distanciamiento ocurre una desaparición del "yo poético, el hablante convencional de la lírica. El hablante del artefacto es cualquiera... El poeta hace hablar a mil personajes anónimos, mil personajes hablan por él" (p. 50). La afirmación se refiere esencialmente a que el carácter fragmentario de las frases de Parra les permite eludir una contextualización específica de sujeto o discurso. Pese a que esta tendencia dialógica de los Artefactos se ha observado copiosamente, rara vez se le presta atención a un descentramiento fundamental de la colección: las ilustraciones de Guillermo Tejeda. Parra concibió el proyecto y se ocupó de enviar numerosas frases al editor Cristian Santa María, pero prefirió mantenerse ajeno al tratamiento visual que recibirían. Tejeda declara (según notas de Binns, 2006, p. 985) que tuvo completa libertad durante su labor y se valió del collage y dibujos propios para ilustrar los artefactos del poeta. Cuenta que las frases no paraban de llegar, y en cierto momento se sintió desbordado, de manera que convino con Santa María que 
los últimos artefactos se imprimirían sin arte, únicamente en la letra del Parra. El producto final fueron 242 postales.

Las frases que conforman los Artefactos son a veces tratadas como obras independientes de su arte. Por ejemplo, Madrid-Letelier (2011) opina:

En las piezas que mueve Parra se producen una serie de operaciones de transgresión de los hábitos de lectura en cuanto a su recepción y la composición de los textos, como también la disociación de la ilustratividad, la mayor parte de las veces la imagen es independiente del texto. (p. 71)

El hecho de que que Parra no haya redactado las frases con un arte determinado en mente no hace prescindible la labor de Tejeda; sin las directrices del poeta, el ilustrador realizó una interpretación visual de los artefactos de acuerdo con su propio juicio, y el resultado no deja de ser un producto completo en el que las imágenes y los juegos con la tipografía matizan de diferentes formas el mensaje textual. Por otra parte, Parra mismo declaró la importancia de la imagen en su proyecto:

Más aún: la última de los artefactos es una etapa que es una combinación de signos lingüísticos con imágenes visuales, y se llaman "artefactos visuales". [...] Lo que me interesa a mí son los esquemas. En este trabajo de retroceso he llegado prácticamente a la época en que el hombre no sabía escribir. La desintegración ha llegado hasta más allá de la propia escritura, del alfabeto. (citado por Morales, 1972, p. 220)

Desde esta perspectiva, disociar texto e imagen atentaría contra el efecto buscado por el poeta. De cierto modo, la ilustración puede ser entendida como otra forma de descentramiento en los Artefactos. No solo la fragmentariedad de las frases acaba con el sujeto poético enunciador, sino que también lo hace la interacción con las imágenes, que despliega nuevos significantes en el producto terminado. En este ensayo se desarrollará la heterogénea pluralidad de pensamiento que reina en los Artefactos en relación con las imágenes de Tejera. Al utilizar una distancia irónica de su "yo", Parra esgrime en su obra una amplia y contradictoria gama de ideas que encuentran un nuevo desarrollo en el diseño visual que las enmarca. Las imágenes permiten abrir nuevos significantes, y acaso cerrar algunos, dentro de la subversión del discurso poético operada por el chileno.

\section{LA INFINITA IRONÍA DE LOS ARTEFACTOS}

Uno de los rasgos más notables de la obra poética de Parra es su uso de la ironía. Sobre el uso de este recurso en la obra del chileno, Grossman (1975) afirma:

These ironic signals consist of the extremely banal objects and actions which evoketheimprisonment, the prosaic language that the protagonistuses to describehis suffering (clichés, inane understatements or jargon), and the inept, evasive rationalizations which he offers in selfjustification. Because of their essentially comic quality, all of the ironic signals are violently incongruous with the protagonist's despair, laying the foundation for the feeling of distance between the observer and the persona. (p. 155) 
Tiene lugar, entonces, una mezcla y alternación de lo sublime con lo prosaico, de lo infinito con lo finito. Por ejemplo, en el poema “Recuerdos de juventud", dice Parra (2006):

¡A dónde ir entonces!

A esas horas el comercio estaba cerrado.

Yo pensaba en un trozo de cebolla visto durante la cena,

y en el abismo que nos separa de los otros abismos. (p. 45)

La imagen de la cebolla observada en un contexto plenamente cotidiano, con sus incontables capas, sirve como evocación de distancias infranqueables que se suceden una tras otra. Como indica Grossman (1975), en Parra se llega a lo profundo a través de lo prosaico; parece ocuparse de perseguir las fisuras existenciales que subyacen en los aspectos más conocidos y establecidos de la vida. Es pertinente recordar el recurso que Costa (1998) señala como frecuente en la poesía de Parra:

Es como si hubiera dos niveles de discurso, uno narrativo en voz alta y otro reflexivo en voz baja, del poeta hablando consigo mismo: un monólogo exterior y un monólogo interior, estableciéndose entre ellos una suerte de diálogo. (p. 14)

Por un lado está el poeta casi afirmando en voz alta, casi prosaicamente: “ $\mathrm{i}$ A dónde ir entonces!"; pero por otro, los pensamientos que desarrollan impresiones íntimas y mucho más profundas. Ambas se alternan de forma irregular y le dan a la poesía de Parra ese carácter a la vez humorístico y profundo.
En los Artefactos, la ironía opera a través del uso de imágenes y frases que resultan conocidas al lector común, y a partir de ellas se despliega una subversión que las pone en riesgo. En este mismo sentido, Man (196) comenta sobre la ironía: "The irony is the radical negation, which, however, reveals as such, by the undoing of the work, the absolute toward which the work is under way" (p. 183). Parra realiza una negación y sátira de representaciones populares o familiares; no obstante, al utilizarlas dentro de su misma ironización, las reivindica de cierta forma. No por nada afirma Carrasco (1999):

El antipoema exige siempre una lectu-
ra mediatizadora, asociativa, relacional,
pues interpone entre su texto base y el
lector otros textos, lenguajes, referen-
tes, que funcionan como una especie de
prisma o imán que atrae los elementos
que lo constituirán. (p. 141)

Desde su carácter breve, una lectura mediatizada de los artefactos es necesaria para que estos desplieguen su potencial: la comprensión de ciertos referentes o la realización de asociaciones con un contexto apenas latente dentro del texto-imagen (figura 1).

Figura 1. Artefacto: burla de la devoción cristiana

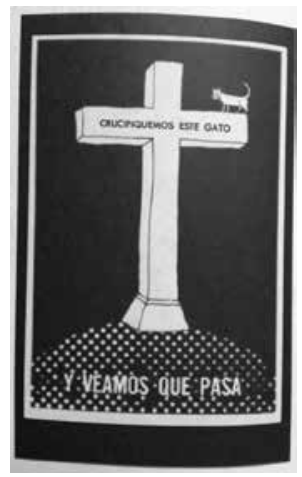


Para lograr su objetivo (la burla), el artefacto necesita que el lector tenga el referente del destino de Jesucristo, que comprenda la supuesta grandeza de su sacrificio, que reconozca el signo de la cruz y, también, por qué no, que asuma la insignificancia de un gato. Una vez se cruza este necesario umbral de mediaciones, se comprende la banalización a la que apunta Parra; levanta el interrogante de si todo el significado que representa la crucifixión no puede crearse alrededor de la figura de un simple gato. Cabe recordar la observación de Muecke (1982): “Irony is saying something in a way that activates not one but an endless series of subversive interpretations" (p. 31). El poeta chileno no afirma categóricamente que el principal símbolo del cristianismo sea una creación arbitraria; en cambio, interroga burlonamente e instiga incontables interpretaciones subversivas sobre los fundamentos de la religión: la posibilidad de "crear" una nueva en el presente, el carácter divino de Jesús, el significado trascendental de la cruz [...] Parra no niega abiertamente la sacralidad cristiana; sugiere que la cruz es más importante que el crucificado, y, al instrumentalizar el símbolo, atenta contra su significado.

La ironía de la frase de Parra se intensifica por el diseño de Guillermo Tejera: la cruz adquiere mayor importancia por ser blanca en un fondo negro y estar en una especie de cima; no obstante, lo que la soporta son apenas puntos, como indicando una debilidad subyacente. Por otra parte, el gato es pequeño comparado con el tamaño de la cruz, lo cual le da un carácter de insignificancia; es igualmente importante que esté a la derecha, casi al borde de la cruz, de manera que opera como un carácter desequilibrante en la que de otra manera sería una imagen simétrica.
Por lo tanto, en los Artefactos hay un despliegue de ideas esquemáticas en el que resulta fundamental el diálogo con el lector, quien debe interpretarlos y desplegar su potencialidad. Si se fuera a tener en cuenta en ellos el comentario de René de Costa sobre la alternancia de un monólogo interior y exterior, se podría decir que en esta colección de texto-imagen, Parra se ocupa de la voz exterior y la convierte en provocadora de una interior en el lector; hay una propuesta abierta de sugerencia más que de expresión franca y directa. Así lo señala Mereles Olivera (2003):

\begin{abstract}
Este texto absoluto, esta obra en movimiento u obra abierta como le llama Umberto Eco, se determina en los Artefactos por su forma de postal que porta un patrimonio cultural, un lenguaje colectivo y liberador cuya continuidad es irrestricta y comparable a la de un caleidoscopio de múltiples combinaciones y múltiples sentidos. (p. 95)
\end{abstract}

Esta apertura en la obra de Parra es creada por su uso de la ironía, que ilumina para el lector el camino de interminables interpretaciones subversivas, ayudadas por las imágenes de Tejera. Una consecuencia de esta heteróclita estructura de los Artefactos es que su apertura es tal que con frecuencia cae en la contradicción; ilumina tantos caminos a un mismo tiempo que destruye la concepción de un pensamiento unificador detrás de la obra. La ironización es tal que extraña por completo al sujeto enunciador. Salvador Jofre (1975) observa lo mismo:

Es obvio, pues, que una poesía que rompe radicalmente con la problemática del sujeto: "el autor de los artefactos 
puede ser cualquiera", una poesía hecha para escribirse en las paredes de las calles, para recitarse como consigna, en el ámbito de la ideología burguesa tenga que ser una poesía imposible. (p. 134)

El centro de esta obra no está, por tanto, en el mismo Parra, sino en su capacidad de provocador de impresiones e ideas en el lector. Y el primer lector de los Artefactos, su primer y más importante intérprete, fue Guillermo Tejeda. Así como Parra utiliza referentes populares en sus frases, Tejeda hace con frecuencia uso del collage. Con esta técnica continúa el proyecto de "reciclar" y reelaborar elementos previamente existentes (sean recortes de revistas, ilustraciones o tipografías reconocidas) para remitirse al bagaje cultural del lector y sugerirle nuevos modos de interpretación. En el siguiente apartado se estudiarán estos modos de evocación creados por el texto en interacción con la imagen.

\section{SubVERSión VISUAL Y TEXTUAL}

Durante las décadas del sesenta y setenta, a Nicanor Parra le tocaron años agitados para vivir. El surgimiento de la izquierda comunista como la posición favorecida por los intelectuales contrastó con la derecha radical que se manifestó en dictaduras y que fue lo que posibilitó la influencia norteamericana en las políticas nacionales. Aunque no fue un militante acérrimo, Parra estaba asociado con la izquierda y mantuvo relaciones amigables con el gobierno cubano posrevolucionario, el bastión comunista latinoamericano más importante. Esto cambió en 1970, cuando, luego de dar una conferencia en la
Biblioteca del Congreso en Washington, el poeta chileno terminó en una recepción en la Casa Blanca con Patricia Nixon como anfitriona. La invitación le valió la execración por parte del régimen cubano y de numerosos intelectuales (como Antonio Skármeta) que condenaron su supuesto servilismo al Imperio. Parra emitió una disculpa pública, pero después simplemente se distanció de la discusión y “terminó por afianzarse en su defensa del poeta como país independiente" (Binns, 2006, p. LxI). Los Artefactos sirvieron como testimonio de la reivindicación de su individualidad y libertad de pensamiento. Pero su crítica no fue explícita, sino que la ejecutó con su habitual ironía. Como se observó anteriormente, esta le permite extrañarse del mensaje en cuestión y, al tiempo que levanta interrogantes, subvierte los paradigmas establecidos. La figura 2 sirve como ejemplo.

Figura 2. Artefacto: unión de la derecha y la izquierda

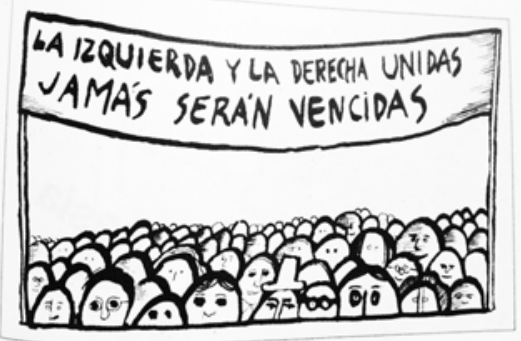

La frase transforma al popular cántico de batalla "El pueblo unido jamás será vencido"; pero al hacer una referencia a la unión de la "derecha" y la "izquierda" juntas como invencibles, alude a la imposibilidad de escapar de este maniqueísmo en que él mismo se vio atrapado. También indica una suerte de igualación entre ambas alas políticas, que en un ambiente polarizado donde 
se desprecia a una o a otra, resulta ofensivo para ambas partes. La ilustración de Tejeda, por otra parte, retrata a una masa sin rostros ni caracterización: no podemos ver sus rostros ni saber si se tratan de personas ricas o pobres; sus cabezas se multiplican hasta un horizonte vacío, sin darnos mayor información sobre su origen o dirección. Esta descontextualización es especialmente significativa si se compara con la obra Operarios de la brasilera Tarsila do Amaral (pintada en 1933):

Figura 3. Operarios, de Tarsila do Amaral

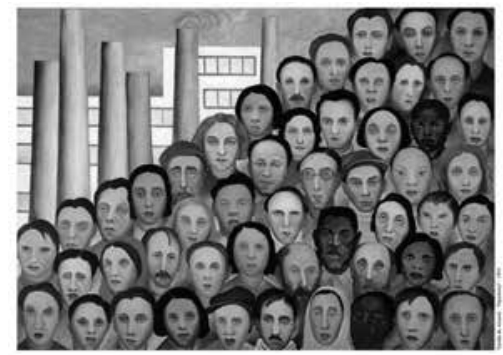

Desde el título Operarios reconocemos que los rostros son de trabajadores de una fábrica, lo que por demás sirve como telón de fondo. En una lectura de izquierda a derecha se observa cómo estos rostros aumentan en cantidad, lo cual puede dar una sensación de la fuerza creciente del proletariado en una época de industrialización en Brasil. Asimismo, los rostros parecen cansados y representan a sujetos de las etnias y edades diversas. En cambio, la ilustración de Tejera enfatiza el anonimato y la descontextualización; la masa de esa izquierda y derecha unidas no revela para donde ir y se extiende "plana" hacia el horizonte.

La obra de Tarsila do Amaral se integra deliberadamente en un contexto sociopolítico al retratar el rostro de obreros. La frase de
Parra alude a las dos alas políticas de su tiempo, pero de forma irónica, mientras que la ilustración de Tejera expresa ese vacío ideológico que supone la hipotética unión propuesta por el poeta. Indudablemente, ambas obras llaman a la interpretación, pero en el artefacto es evidente su clave irónica y declara su apertura para llamar a interpretaciones subversivas del discurso político del momento, apoyado en la referencia al conocido cántico obrero. Mientras tanto, la imagen de Tejera no solo "representa" la frase de Parra, sino que abre nuevas relaciones para el lector, sea en alusión a la obra de Tarsila de Amaral o a la calidad de las masas movidas por el manifiesto.

Aunque los Artefactos versan sobre temas muy diversos, muchos de ellos aluden a la polaridad entre derecha e izquierda y permiten perfilar la postura distanciada de $\mathrm{Pa}$ rra; satiriza alternativamente a una u otra ala política sin concretar una crítica precisa (figura 4).

Figura 4. Artefacto: crítica política

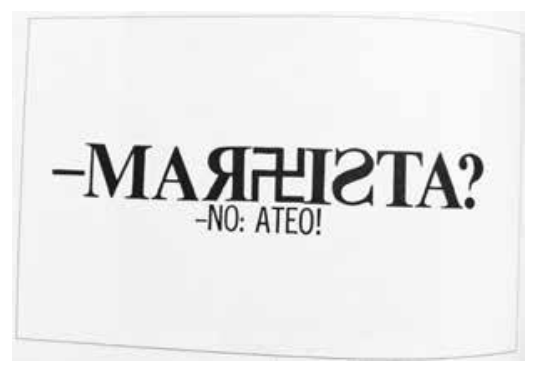

El anterior artefacto se contradice explícitamente con el siguiente. 
Figura 5. Artefacto: crítica política

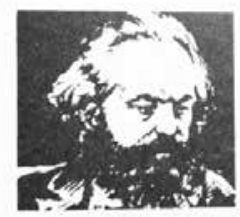

BUENO BUENO

pongámosle que soy marxista

En la figura 4 hay un contraste entre lo que puede ser un ateísmo puro con un ateísmo propio de los marxistas. No obstante, en otro nivel, puede interpretarse que en el artefacto se entiende el marxismo como una suerte de religión ajena a quien responde a la pregunta. En este sentido, la frase ironiza la devoción casi sagrada que inspira el partido de la izquierda. Al mismo tiempo, Tejera introduce un elemento intruso: la cruz esvástica, que opera una apertura hacia la ideología fascista como parte del comunismo marxista.

Por otra parte, en la figura 5, la voz enunciadora se declara marxista, con ese dejo irónico que da "Bueno bueno", como si lo afirmara por simple ánimo de complacer. El efecto es enfatizado por las mayúsculas. En este caso, Tejera acompaña el texto con un grabado de Marx, que si bien puede ser tomado como simple decoración, también permite pensar al filósofo como posible enunciador del mensaje. El resultado es un Marx apenas convencido de eso que llaman "marxismo".

Dentro de ese juego con las ideologías políticas, Parra no rehúye de la crítica a los Estados Unidos como símbolo del capitalismo (figura 6).
Figura 6. Artefacto: crítica a Estado Unidos

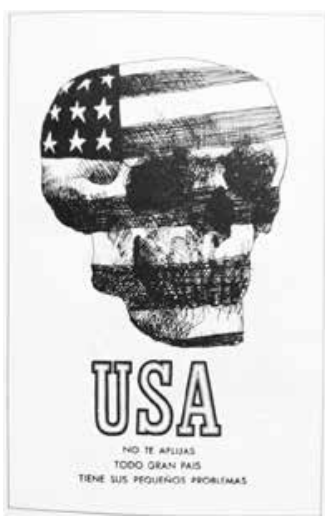

Si solo se tiene en cuenta el texto de la figura 6, se puede notar que la ironía está en el contraste entre "gran país" y "pequeños problemas". Los antónimos marcan un contraste que ponen en duda su seriedad, pero este carácter está especialmente acentuado por la enorme y espectral calavera marcada por la bandera de los Estados Unidos; la sugerencia sobre el posible carácter mortífero de este país es casi inevitable. Por otra parte, sin ser una parodia exacta, la diagramación de Tejera y la tipografía se asemejan al célebre cartel norteamericano utilizado durante la Primera y Segunda Guerra Mundial para reclutar soldados (figura 7).

Figura 7. Cartel estadounidense para reclutamiento de soldados

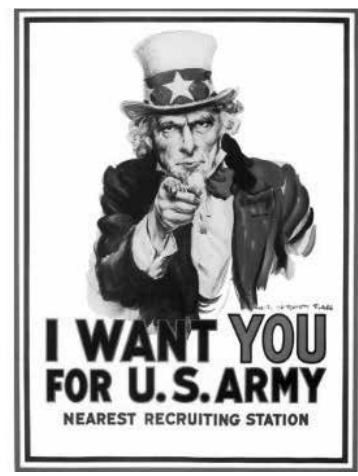


Si se asocian ambas imágenes, es posible entablar un vínculo entre los presuntos pequeños problemas de Estados Unidos con su potencial bélico. La alusión de Tejera al póster del tío Sam no es necesariamente explícita o intencional, pero el uso del formato de poster en la diagramación es una convención que permite extender un puente entre dos mensajes opuestos y, en este caso, subvertir el mensaje nacionalista americano.

Si el artefacto de la figura 6 puede ser calificado de antiyanqui y los de las figuras $4 \mathrm{y}$ 5 de anticomunistas, podría acusarse a Parra de un mero arlequín que esgrime ideas contradictorias caprichosamente; sin embargo, el proyecto general de los Artefactos precisamente supone una difuminación del sujeto, $\mathrm{y}$, con esto en consideración, no puede haber una contradicción si no es una sola voz la que habla.

\section{Conclusiones}

Sobre los Artefactos, Morales (1972) opina: "El artefacto resulta ser una expresión de ausencias: ausencia de mundo, ausencia de realidad, ausencia de personaje" (p. 125). Si hay una marcada ausencia dentro del carácter fragmentario de la obra, también es necesario señalar que esta ausencia sirve como llamado a la interpretación y a una inestable unidad. Los artefactos no son tanto productos ideológicos como semillas de subversión que, gracias a su clave irónica, instan al lector a desplegar y recrear sus significados.

Dentro de esta noción de "obra abierta", sin un sujeto unificado que enuncie una ideología estable, las ilustraciones de Guillermo Tejera sirven como una forma adicional de descentramiento. El ilustrador innovó e interpretó las frases de Parra y, dentro de las connotaciones visuales que le dio, abrió en los textos nuevos referentes que enriquecen el carácter alusivo que tienen de por sí. Si las frases de Parra cuentan con cierta autonomía, también es cierto que su naturaleza es una que insta a la interpretación, y su tratamiento gráfico solo intensifica su capacidad de sugerir.

En este artículo se trabajó la heterogeneidad propuesta en los Artefactos, principalmente en referencia con el conflicto político, pero la obra de ninguna forma se limita a este ámbito; Parra extiende sus ironías a campos más diversos que pasan por la poesía misma, la belleza, la literatura o la vida cotidiana, entre muchos otros (figura 8).

Figura 8. Heterogeneidad de la propuesta de los Artefactos

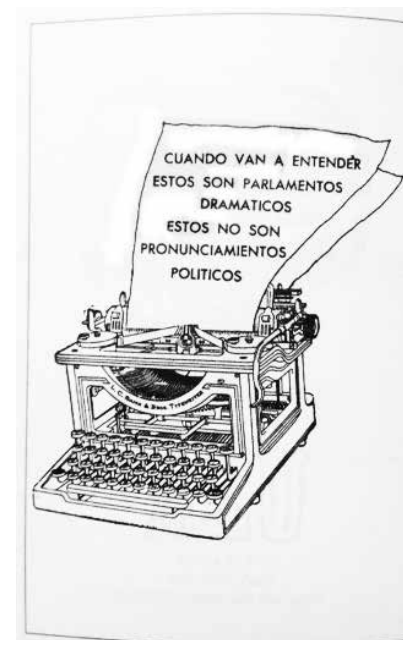

No son pronunciamientos políticos los que tienen lugar en los Artefactos, pero tampoco éticos o estéticos; es una obra que atenta contra la posibilidad de un sistema estable 
y homogéneo. Como el gran dramático Shakespeare, Parra utiliza máscaras y las abandona, esboza ideas y las contradice. De la misma forma que Borges supuso un vacío en la identidad del bardo subyacente al exuberante panorama de sus obras, hay un vacío de identidad en los Artefactos, y dentro de este descentramiento fundamental radica su valor.

\section{REFERENCIAS}

Binns, N. (2006). Notas. En Nicanor Parra. Obras completas \& algo +. Barcelona: Círculo de Lectores.

Borges, J. L. (1989). Obras completas II. Buenos Aires: Emecé.

Carrasco, I. (1999). Para leer a Nicanor Parra. Santiago de Chile: Cuarto Propio.

Costa, R. de (1998). Para una poética de la (anti) poesía. En Nicanor Parra. Poemas y antipoemas. Madrid: Cátedra.

Grossman, E. (1975). The antipoetry of Nicanor Parra. Nueva York: New York University Press.
Ibáñez-Langlois, J. M. (1972). Prólogo. En Nicanor Parra. Antipoemas. Barcelona: Seix Barral.

Madrid-Letelier, A. (2011). Gabinete de lectura: poesía visual chilena. Santiago de Chile: Metales Pesados.

Man, P. de (1996). The Concept of Irony. En Aesthetic ideology. Minneapolis, Londres: University of Minnesota Press.

Mereles Olivera, S. (2003). Cumbres poéticas Latinoamericanas. Nicanor Parra y Ernesto Cardenal. Nueva York: Peter Lang Publishing.

Morales, L. (1972). La poesía de Nicanor Parra. Santiago de Chile: Universidad Austral de Chile, Editorial Andrés Bello.

Muecke, D. C. (1982). Irony and the ironic. Londres/Nueva York: Methuen.

Parra, N. (2006). Obras completas $\mathcal{E}$ algo +. Barcelona: Círculo de Lectores.

Salvador Jofre, Á. (1975). Para una lectura de Nicanor Parra. Sevilla: Universidad de Sevilla.

Van Hooft, K. S. (1974). The Artefactos of Nicanor Parra: the explosion of the antipoem. Bilingual Review, 1(1), 67-80. 